\title{
Managing weighty issues on lean evidence: the challenges of bariatric medicine
}

The term "bariatric medicine" (from the Greek baro, meaning weight) is increasingly being used to describe the field of medicine that deals with the multitude of medical problems encountered in morbidly obese patients.
$\mathrm{O}$ besity currently affects more than 300 million people worldwide, and by the end of this decade as many as $20 \%$ of the adult population in North America may have a body mass index (BMI) greater than $40 \mathrm{~kg} / \mathrm{m}^{2}$. Thus, physicians and other health care workers will be delivering health care to a growing number of obese and morbidly obese patients.

Over the last 50 years, demographic changes toward a growing elderly population, together with the recognition that a host of medical problems encountered in elderly people require special diagnostic and therapeutic approaches, led to the stillyoung discipline of geriatric medicine. Along similar lines, the term "bariatric medicine" (from the Greek baro, meaning weight) is increasingly being used to describe the field of medicine that deals with the multitude of medical problems encountered in morbidly obese patients.

Diagnosing many common medical conditions, although straightforward in nonobese patients, can be fraught with difficulty in morbidly obese people because little is known about the sensitivity and specificity of diagnostic tests in this population. For example, in one study, almost two-thirds (24/39) of patients with a BMI greater than $40 \mathrm{~kg} / \mathrm{m}^{2}$ who presented with severe symptoms and signs of chronic venous insufficiency had no detectable anatomic evidence of venous insufficiency with Doppler ultrasonography. ${ }^{1}$ In a comparison of angiography findings with precatheterization noninvasive functional test results (nuclear myocardial perfusion or stress echocardiography) in morbidly obese $(n=110)$ and nonobese $(n=4868)$ patients with suspected coronary artery disease, the prevalence of coro- nary artery disease was lower among the obese patients ( $45 \%$ v. $72 \%),{ }^{2}$ which may indicate a higher prevalence of falsepositive noninvasive test results in that group. Newer radiological tests such as electron beam tomographic screening of coronary artery calcium require adjustments for BMI to decrease the number of false-positive results. ${ }^{3}$ However, obtaining imaging studies such as CT or MRI is often impossible for morbidly obese patients because of the size and weight limitations of the machines. Oversized equipment is unavailable in most hospitals. These limitations call for more research into diagnostic algorithms, tests and reference ranges for morbidly obese patients, to avoid misdiagnoses and to ensure optimal care.

Of major concern is the lack of data on clinical aspects of morbid obesity and the medical and surgical management of comorbidities. Indeed, except for studies specifically focusing on weight loss, obese people are generally underrepresented in clinical trials. As a result, the majority of clinical practice guidelines, even for conditions commonly found in obese patients (e.g., hypertension, diabetes mellitus, asthma, ischemic heart disease, venous thrombosis and neuropsychiatric disorders) fail to make specific recommendations for patients with morbid obesity that go beyond a rather general appeal for weight loss. This issue is far from trivial, as obesity significantly affects the pathophysiology and pharmacodynamic response in a multitude of medical conditions. For example, in obese patients with essential hypertension $(n=$ $10), \beta$-blockers were found to effect a better diastolic response than calcium-channel blockers; ${ }^{4}$ however, such patients may be at increased risk of renal hyper- filtration and microalbuminuria and therefore may require reninangiotensin blockade. ${ }^{6}$ Another example is gastroesophageal reflux disease, where the pathophysiology in obese patients (increased intra-abdominal pressure, hiatal hernia, vagal abnormalities) may be distinctly different from that in nonobese patients. ${ }^{7}$ Responses to medications may be different, as metoclopramide may fail to decrease gastric volume or raise $\mathrm{pH}$ in obese patients. ${ }^{8}$ Similarly, although self-reported asthma is more frequent at higher BMI levels, obese individuals paradoxically are at lowest risk for significant airflow obstruction, ${ }^{9}$ and much of the respiratory symptoms may indeed be due to nocturnal aspiration of gastric reflux. ${ }^{10}$ Thus, asthma not only may be overdiagnosed in the obese population but, if present, may require a different approach to management.

Few studies have examined the effects of excess weight on pharmacokinetics and pharmacodynamics, even of medications commonly used in obese patients. When available, studies are often limited to a few healthy obese volunteers or to patients with relatively uncomplicated health status. The pharmacokinetics of drugs in obese patients may be significantly influenced by differences in tissue distribution, hemodynamics, blood flow to adipose, splanchnic and other tissues, plasma composition, or liver and kidney function. This is of particular concern with drugs that have narrow therapeutic indices (e.g., cytostatic drugs) or minimal effective concentrations (e.g., antibacterial drugs, injectable contraceptives). Clearly, a systematic assessment of drug doses and clinical outcomes in obese patients is overdue.

In addition, there are virtually no studies of the outcomes 
of critically ill obese patients in intensive care units (ICUs). Commonly used mortality scoring systems for adult ICU patients fail to predict increased mortality among morbidly obese patients, perhaps because none of these scores included data on morbidly obese patients in their development.

\section{Virtually all existing diagnostic criteria and algorithms will need to be revalidated in the obese population}

Thus, unlike issues related to health care for other subgroups of the population (e.g., elderly people), most health care issues concerning obese patients have yet to be studied. Virtually all existing diagnostic criteria and algorithms will need to be revalidated in the obese population, and where physical limitations hinder the use of diagnostic imaging technology, new strategies will have to be developed to deal with very obese people. Licensing authorities may have to make the pharmacokinetic and pharmacodynamic evaluation of new drugs in obese individuals mandatory before allowing the use of these drugs in such patients. Inclusion of obese and very obese subjects in clinical trials should be actively supported. In short, most of what we know about medicine will need to be re-evaluated to ensure optimal medical care of obese patients. These activities should not distract from the continuing research needs of finding new and more effective medical and nonmedical approaches to preventing and combatting the obesity epidemic.

\section{Arya M. Sharma}

Canada Research Chair

for Cardiovascular Obesity Research and Management

McMaster University

Hamilton, Ont.

Acknowledgements: Arya Sharma is the recipient of a Canada Research Chair Award and receives support from the Canadian Institutes of Health Research and the Heart and Stroke Foundation of Canada.

Competing interests: Arya Sharma acts as a speaker and consultant and has received research support from many companies developing metabolic and anti-obesity drugs, including Abbott Laboratories, SanofiAventis, Johnson \& Johnson, GlaxoSmith Kline, Novartis, Merck Frosst, Pfizer, Boehringer Ingelheim, Bristol-Myers Squibb, Solvay, Hoffman-La Roche, Servier and AstraZeneca.
References

1. Padberg F Jr, Cerveira JJ, Lal BK, Pappas PJ, Varma S, Hobson RW II. Does severe venous insufficiency have a different etiology in the morbidly obese? Is it venous? 7 Vasc Surg 2003; 37:79-85.

2. McNulty PH, Ettinger SM, Field JM, Gilchrist IC, Kozak M, Chambers $\mathrm{CE}$, et al. Cardiac catheterization in morbidly obese patients. Catheter Cardiovasc Interv 2002;56:174-7.

3. Sevrukov A, Pratap A, Doss C, Jelnin V, Hoff JA, Kondos GT. Electron beam tomography imaging of coronary calcium: the effect of body mass index on radiologic noise. 7 Comput Assist Tomogr 2002;26:592-7.

4. Schmieder RE, Gatzka C, Schachinger H, Schobel H, Ruddel H. Obesity as a determinant for response to antihypertensive treatment. $B M \mathcal{F}$ 1993:307:537-40.

5. Valensi P, Assayag $M$, Busby $M$, Paries J, Lormeau B, Attali JR. Microalbuminuria in obese patients with or without hypertension. Int 7 Obes Relat Metab Disord 1996;20:574-9.

6. Sharma AM. Is there a rationale for angiotensin blockade in the management of obesity hypertension? Hypertension 2004;44:12-9.

7. Barak N, Ehrenpreis ED, Harrison JR, Sitrin MD. Gastro-oesophageal reflux disease in obesity: pathophysiological and therapeutic considerations. Obes Rev 2002;3:9-15.

8. Laws HL, Bryant JW, Palmer MD, Boudreaux AM, Donald JM Jr, Wheeler AS. Effects of preoperative medications on gastric $\mathrm{pH}$, volume, and flora. Ann Surg 1986;203:614-9.

9. Sin DD, Jones RL, Man SF. Obesity is a risk factor for dyspnea but not for airflow obstruction. Arch Intern Med 2002;162:1477-81.

10. Gislason T, Janson C, Vermeire P, Plaschke P, Bjornsson E, Gislason D, et al. Respiratory symptoms and nocturnal gastroesophageal reflux: a population-based study of young adults in three European countries. Chest 2002; 121:158-63.

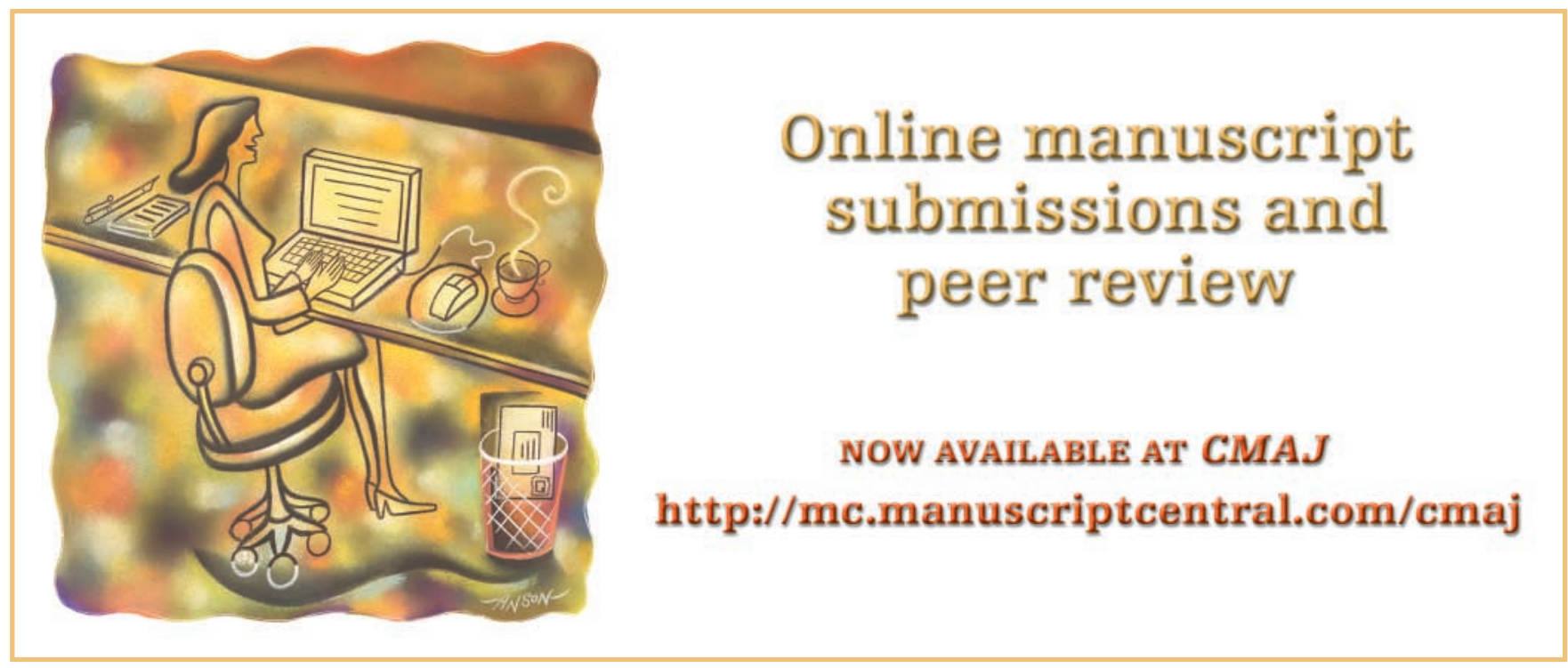

